\title{
The Revival of Live TV: Liveness in a Multi-platform Context
}

\section{Introduction}

Web 2.0 and increases in time-shifted and on-demand content across devices are reshaping the ways in which viewers access, consume and interact with audiovisual content. These multi-platform affordances and changing viewing behaviours impact on the ways that the TV networks produce, schedule, and deliver TV programmes and associated content as has been analysed by scholars both in an American and a British context (see among others Author Removed, 2013, 2014; Jenkins, 2006; Lotz, 2009; Caldwell, 2003, 2006, 2011; Bennett, 2007, 2008, 2011; Bennett and Strange, 2008, 2011; Bennett et al., 2012; Chamberlain, 2011; Doyle, 2011, 2013a, 2013b; Ytreberg, 2009; Steemers, 2004, 2014; losifidis et al., 2005).

The uptake of internet-enabled portable media platforms and devices - iPhones/smartphones, laptops, PC and iPads/tablets - both complicates and complements these developments. Today, $54 \%$ of viewers in the UK watch audiovisual content on a laptop, $49 \%$ on a tablet and $39 \%$ on a mobile phone at least once a week. In addition, $37 \%$ of all Brits, and $57 \%$ of $16-24$ year olds, habitually 'media mesh' on two or more screens simultaneously, and interact directly with the programmes they watch on one screen, through another device. Viewers for example text/SMS, chat, tweet, social network, or interact direct with audiovisual content on one screen through affiliated sites or apps on another (Ofcom, 2013a: 141). To illustrate this, during the 2014 Sochi Winter Olympics the BBC recorded 5 million 'Live'/As it happened' unique browser views in the UK and $6.5 \mathrm{~m}$ globally, and the official BBC hashtag was tweeted over 3.5 million times (data from the BBC Press Office, August 2014). Similarly in 2013, the $X$ Factor series' live transmissions attracted an average volume of 406,000 tweets per programme; and the 2013 Wimbledon Men's tennis final was watched by 17.3 million people in the UK, whilst a further 1.1 million people worldwide tweeted at least 2.6 million times about the match, and 'liked' and posted over 20 million times on Facebook (Kleinman, 2013; Ofcom, 2013a: $33-41$ and 150-152). The scale of these new viewing patterns, practices and interactions necessitates a review of how live television is understood, used and strategised by broadcasters. 
This article examines how the notions of liveness and live TV are being reshaped within this context. Focusing on the BBC and Channel 4, the UK's two publicly owned TV networks, the article explores how and why these two public service networks are reinventing and promoting liveness and in particular live media events (as defined by Dayan and Katz, 1992: 4-10) across platforms and devices. The article will argue that rather than seeing live television as a phenomenon of the past that has been rendered less relevant in the multi-platform world, the British public service channels are using live TV coverage of major events as a key part of their multiplatform strategy. Indeed, the live broadcasting of media events gives the TV networks a clear competitive edge over the streamed content and VOD services available from online providers such as YouTube, Netflix and Amazon Prime.

The research presented here is based on a series of interviews with multi-platform executives and producers within the BBC and Channel 4, conducted between 2010 and August 2014 as well as viewing data, browser imprints and social media activity, obtained from these broadcasters' press offices. It also draws on publicly available data and statistics about media use around live events from the British telecommunications regulator Ofcom and PACT, the UK's trade association for creative content producers, as well as BBC's and Channel 4's multi-platform strategies as outlined in their vision statements and annual reports. This data is analysed in relation to the actual coverage of live events on both channels. The focus of this article is the analysis of live events and live TV programmes in the first quarter of 2014, specifically the BBC's 2014 Sochi Winter Olympics, Channel 4's Sochi Winter Paralympics and Live from Space season in February and March 2014 across four screens (TV, laptop/desktop, tablet/iPad and iPhone/smartphone). The live coverage of these events was explored in a series of short case-studies, or netnographies (Kozinets, 2010), which observed and recorded the transmission of live events across multiple screens simultaneously, in real time. There will also be references to other programmes that were advertised and presented as 'live', but were not transmitted in real time, as well as other live broadcasts from the summer of 2014.

The coverage of live events described here in a British context echoes the delivery of live events in other countries with public service media providers for example Australia, Denmark and Finland. 
It is important to note here, that 'liveness' and 'live TV' in this article are defined as the live broadcast of an event that is transmitted to viewers and users in real time as it unfolds ${ }^{1}$.

\section{Liveness on Television}

Live TV transmissions and the notion of liveness have always been central to the proposition and aesthetics of television (Auslander, 2008: 12-13; Crisell, 2012: 1; Levine, 2008: 394-395; Caughie, 2000: 32; Marriott, 2007). In the 1930s and 1940s, all television programmes - from news to drama - were transmitted live (Auslander, 2008: 15; Caughie, 2000: 30-32). The introduction of recording equipment in the mid 1950s changed the technical capabilities and the aesthetics of television, as well as commissioners' and schedulers' ability to commission, plan, and schedule programmes. With this followed a readjustment of the centrality and function of liveness and live TV. Live transmissions remained important and relevant for certain genres, for example the immediacy and currency of news and sports mean that a most of this - $97 \%$ and $92 \%$ respectively - is watched live to this day (Ofcom, 2013a: 148). The value of live transmissions is also reflected in the rights of its sales value with live being $99 \%$ of linear rights (Boyle, 2015: 2). The planning, development and resources involved in the production of other genres, such as entertainment, drama and documentary, meant that it became more efficient to pre-record (sometimes 'as live' and sometimes as a film) much of this material.

For broadcasters, this ability to record television programmes on film and video tape not only brought about changes in technology and practical production conditions, it also offered new aesthetic possibilities (Caughie, 2000: 32) and created higher levels of precision and quality for some programme genres. It had an economic rationale too. Highlights of sports events could be rerun as part of news programmes; footage from news items could be recycled later in news bulletins or current affairs programmes; and dramas, documentaries and children's programmes could be retransmitted and sold to other territories. This spread production costs, offered more avenues for profit or recoupment of initial investment but also turned programmes into products (Steemers, 2004: xiv; losifidis et al., 2005: 19). Video and AV recorders in the 1980s, DVD and Blu-ray in the 1990s and DVRs, streaming and Video on Demand (VOD) today have all precipitated these trends (Doyle, 2013b: 73-99).

The affordances of multi-platform broadcasting and Web 2.0 have further transformed the notion of liveness. In his article 'Extended Liveness and Eventfulness in Multi-platform Reality Formats', Espen Ytreberg analyses how 
European multi-platform reality formats are constructed and designed to allow audiences to interact with and revisit programmes online, and in this way enhance and amplify them as a media events. The dynamics between on and offline as well as on- and off-air interaction extend the perceived liveness of these formats between programmes and their temporal life beyond their on-air transmission (2009). In the UK context and especially in relation to documentary and factual content, James Bennett and Niki Strange have demonstrated how the BBC drives traffic between platforms (in their analysis TV and web) to create 360-degree viewing experiences across platforms and content. This, they argue, not only creates a richer viewing experience but is also used to fulfil public service remits (Strange, 2011; Bennett, 2008). With reference to John T Caldwell's second shift aesthetics (2003), both see 360 television strategies as ways to orchestrate user-flows between platforms in a post-linear and digital scheduling landscape (Bennett and Strange, 2008, 2011). In feature films and TV drama productions, the producers, distributors and broadcasters seek to monetise associated content across screens beyond the transmission or release of the actual programme or film as described by, among others, Henry Jenkins (2006) and Jonathan Gray (2010).

Thus, these shifting technologies as well as the corresponding changing cultural and economic paradigms have changed and modulated how live television has been understood and used by the TV broadcasters at different times throughout their history. In line with this, Philip Auslander argues that liveness on television must be seen in its historical and social context rather than as an ontological condition (2008: xii-xiii). Similarly, although the events they describe pre-date the internet, Dayan and Katz' excellent definition and analysis of live media events are pertinent to the analysis here. They describe live media events as a genre in itself that celebrates one-off events and fulfils a series of social functions through enacting, performing and affirming narratives of 'contest, conquest and coronations' (1992).

This article draws on research into both live TV as well as multi-platform programming. It seeks to re-situate and contextualise the notion of liveness and live media events in a mediascape where content on portable devices laptops, smart phones and tablets - is increasingly consumed at the same time as live TV. By exploring how the BBC and Channel 4 are reinventing the notion of live TV in a multi-platform context, this article will argue that today, TV networks are using liveness, one of television's traditional strengths, to fight back and even to regain ground from online content and VOD providers. 


\section{Liveness - Dead or Alive?}

The uptake of digital video recorders, VOD and the proliferation of content online have led some TV commissioners and critics to pronounce the days of live television over. Chapter four in Andrew Crisell's Liveness and Recording in the Media is called 'Television and Recording: Replacing Liveness' (2012: 18) and David Booth, former Vice President for Content \& Programming at MTV has argued that liveness is increasingly irrelevant for audiences who either 'binge on box-sets' (Brundson, 2010) or demand content to be accessible and available immediately, at all times and across platforms through VOD, DVRs and PPV². However, at the same time as more content is being recorded or watched time-shifted, more TV than ever before is being watched, and interacted with or alongside, as it is transmitted. Or, maybe more correctly, the TV is turned on for longer periods of time in British households than ever before. What is clear is that as audiences multitask on a variety of devices simultaneously, more content is being consumed on more devices than ever before (Ofcom, 2013a: 29). James Thickett, Ofcom's Director of Research, sums up:

Our research shows that increasingly families are gathering in the living room to watch TV just as they were in the 1950s - but now delivered on bigger, wider and more sophisticated sets. Unlike the 1950s family, however, they are also doing their own thing. They are tweeting about a TV show, surfing the net or watching different content altogether on a tablet....Just a few years ago, we would be talking about last night's TV at work or at school. Now, we're having those conversations live while watching TV using social media, text and instant messaging. (Ofcom, 2013b)

This has had a profound impact on all aspects of television. For the TV networks it has led to 'two-screen programming' and strategic priorities to commission, schedule and distribute content across platforms, devices and VOD players. For the audiences this has meant a richer content-consumption experience through increased interaction, accessibility and availability of content. This shift has also led to a redefinition of both TV stations' and users' understanding of what constitutes 'live television' - and what it might become. Liveness may be dead for some of the smaller, re-run or niche channels, but for the TV networks that still that command reach and large audience shares - in the UK the BBC, ITV and Channel 4 - liveness is once again becoming one of the defining characteristics and unique selling points of television in a crowded multi-platform mediascape. 


\section{Television - Dead or Alive?}

Since TV went digital and Web 2.0 made social networking and streaming audiovisual content common practices for many, the opportunities for interaction that this might afford have lead to numerous theories about, and experiments with, audience and screen interactions. Initially, the massive scale and success of user-generated content on sites like YouTube, Vimeo and Dailymotion raised the question of whether the internet would render the proposition of television content as well as TV networks and brands obsolete as for example Jeanette Steemers has pointed out (2014). There is little doubt that new content providers like Google, Amazon and Netflix are now important players in the market of delivering audiovisual content across platforms. Increasingly, however, it looks like TV brands and networks are finding new ways to have more, not less power in an online and multi-platform context (Author Removed, 2014; Steemers, 2014; Boyle, 2014; Mosey as cited in Boyle and Whannel, 2010). Today television is, as the title of Bennett and Strange's anthology states, best described as digital media (2011). As the TV brands and networks expand their presence online, and deliver content across platforms, devices and screens, they are also redeploying and using the core strengths of their medium liveness and reach - to regain market shares and viewing figures. Moreover, they are using and enlisting the affordances of mobile devices and activity on apps and social networks to hype, gather momentum and accumulate free exposure and advertising around their programmes. This is especially the case in the coverage of live events, where broadcasters not only outsource and sometimes free-ride on social network activity, they also actively encourage it - crucially without seeking to host or curate this on their own platforms or sites. In doing so they boost attention around these live events, and in this process accumulate viewers, as well as build and amplify the sense of their own cultural importance and centrality in the mediation of live events.

Speaking at the opening panel session at the FT Digital Media conference in London in 2013, Jeff Bewkes, chairman and CEO of Time Warner, said: 'The digital revolution means TV taking over the internet not the other way around' (Financial Times Live, 2013). In this same interview, he also cancelled out - maybe a bit rashly the differences between devices and stated that tablets and smartphones are just smaller, portable TVs. Bewkes was obviously ignoring the many other different features and affordances that distinguish these devices; however, his view of television as pervasive content across multiple, portable screens, and devices as simply 
mechanisms for delivering this content is helpful in this analysis, because it shifts the focus away from media and platform centricity and allows for broader user and network-orientated perspectives on live media events.

Bewkes comments also resonate with how liveness and live media events are being reinterpreted and strategically redeployed by British TV broadcasters. In a 2010 interview, Channel 4's Head of Creative Diversity Stuart Cosgrove stressed that television both as broadcast institutions and a medium have attributes that the internet does not:

... you need to be increasingly aware of the fragmentation of the industry. That whilst television was usually a kind of unified family experience in the 80 s, families still watch television together usually around bigger events shows, or big kinds of events like X-Factor or Strictly Ballroom, whereas, in Channel 4, the bigger things might have been the final nights of Big Brother... There's these sorts of big live events that people congregate around and so event television is still in place....I think that whilst that's the case, television will still have massive power because it's greatest power is to curate and brand and commission as much as to distribute and circulate... So l'm not a big fan of the idea of 'Poor old telly, it's dead, isn't it?' because there's quite a lot of things that TV does really well that the web's piss at.

(Interview with Author)

Although the TV networks' oligopoly on commissioning and curating audiovisual content is facing increasing competition from Netflix's, Google's and Amazon's recent entry into the commissioning and production of TV drama series, television is still the medium that can reach the largest simultaneous audience across all screens, in real time.

In his inaugural speech regarding his vision for the BBC in October 2013, Director General Tony Hall took Cosgrove's points one step further and called television 'the original social media'. In this address Hall stated that television always has and still does attract mass audiences to live events, but that the BBC will add a new personalised, social media interface and dimension to this:

Nothing can bring the country together quite like television. And so we want the BBC's channels - and BBC One in particular - to be a place where we can share all our national moments. That's why we brought the FA Cup back home to the BBC. And it's why we're going to rethink how we cover big 
events. The phrase 'Live on the BBC' will tell viewers that the experience is going to be a special one... you will also have noticed another trend: towards a much more personal $B B C$; something different perhaps for every single one of us. Not one to everyone, but one to one.....Audiences will be invited to sign in. They'll get personalised recommendations. They'll be able to rate our programmes, to discuss, participate and vote. That will influence what we commission, when we schedule, how we run the BBC. They can become their own schedulers, our next creators, our future innovators. This is the start of something. I don't know where we'll end up, but I want to start the conversation. (BBC, 2013)

Broadcasters are in a unique position to combine the reach of TV as a medium with the reach and affordances of social media to create personalised viewing experiences, as well as attention and a buzz around events. Live TV is especially suited to this, and TV stations are increasingly using the coverage of live events to immerse audiences in its content on whatever device it finds itself, and to further propagate this immersion across screens through social networks.

Hall's vision reflects programming practices and strategies that are already taking place. Since the 2012 London Olympics, the BBC has transmitted the annual Glastonbury Music Festival live across four screens (TV, tablet, mobile and computer). In 2014, Channel 4 transmitted the Winter Paralympics in the same manner and its Live From Space season was aired live from the NASA HQ in Houston and from the NASA space station as it circumnavigated earth with live tweet along. The BBC's multi-platform service covered the Winter Olympics, the World Cup, the FA Cup, Wimbledon and The Commonwealth Games (June and July 2014); along with live music events like the Proms and Glastonbury, as well as the live coverage of the Scottish independence referendum on the 18 $18^{\text {th }}$ September 2014.In February 2015 the BBC celebrated the $30^{\text {th }}$ anniversary of the soap opera Eastenders with a week of live transmitted episodes and in march 2015 Channel 4 transmitted the return and burial of King Richard the III, whose remains were found under a car park in Leicester in 2012, over two days of three hours live transmissions.

Increasingly, the BBC and Channel 4's strategies are to use television's traditional traits - liveness and simultaneous reach - to counter and crowd out competition from online user-generated content and VOD providers like Youtube, Netflix and Amazon Prime across platforms. 


\section{The Delivery of Live Across Devices}

The ways in which live media events are delivered is important. The BBC has created a live online content management system, BBC Live, which the BBC uses to facilitate live TV events across devices. Channel 4 used a similar system for their Winter Paralympics coverage. BBC Live facilitates the coverage of live events across discreet screens. On each screen several live streams are available simultaneously - in Sochi Winter Olympics up to six and at the Commonwealth games up to thirteen streams. The design is such that each screen functions like a TV and viewers simply stay with the content and chose between the various streams on whatever device they are viewing on, in the same manner as they would flick between channels on a TV with the crucial difference that they are now sticking with the same broadcaster. On a TV this selection happens through the Red Button and on laptops and mobile devices by choosing between different live feeds. Alongside these live streams, BBC Live also makes available VOD catch up, additional interactive services and content.

According to Chris Condron, BBC Head of Product and Sports and the creator of the BBC Live delivery system and interface, different devices are simply different content delivery platforms. Therefore the first priority is to make sure that all the action is live and accessible on any device at all times. The second priority is that audiences can watch on one device and screen and use second screens to 'media mesh', and supplement viewing with additional coverage on an additional platform (interview with author, August 2014). Crucially, there is little attempt to engage or drive viewers between platforms or devices. Rather, the idea is to make users stay on whatever platforms and devices they are on and keep them there by either guiding them between different live steams, or encouraging viewers to explore content around the same event on two devices simultaneously.

In these ways the coverage of live events through BBC Live is different from the way liveness plays out in other genres. Of course, the nature of for example the Olympic Games cancels out the need to drive viewers across platforms and devices. With one-off events there is no need to extend liveness, build brand loyalty or nurture audience fandom between series or shows as Ytreberg (2009) describes is the case with reality formats, nor is there an additional need to fulfil public service remits of digital engagement as it can be the case with the documentary and factual content (Bennett, 2008). What these differences in the coverage of different types of 
content flag up, then, is that TV networks' multi-platform strategies and delivery strategies are determined by the nature and genre of the material covered. TV broadcasters have multiple strategies for broadcasting across screens and social media, and these variations are to some extent genre dependent. Therefore, when seeking to understand the strategies of TV networks in the multi-platform mediascape, it is necessary to consider a variety of interrelated strategies with differing degrees of interactivity, and to take into account the genre and type of content in question as well as the manner in which this is communicated and broadcasted.

This is apparent from the Graphic User Interfaces across devices of both the BBC's Sochi Winter Olympics and Channel 4's Paralympics.

\section{Sochi Winter Olympics and Paralympics 2014 - The Revival of Liveness}

Disregarding obvious differences of channel branding, the BBC and Channel 4's coverage of the Sochi Winter Olympics and Paralympics respectively had many commonalities. On all devices - smartphones, computers, tablets and televisions - the users were able to choose between different streams of live events - six on BBC and three on Channel 4 - as well as VOD catch up with previous events. In addition to these live streams from different events, there was further content available online (for mobile phones, tablets and PCs), for example: interactive medal tables; guides to the rules of different sports; as well as mini-documentaries exploring the background of athletes, teams, Victory narratives and production accounts. For example, the BBC featured 'Sochi 2014's most awesome jumps'; 'GB's Yarnold storms to Skeletal Gold'; 'How GB men reached the Olympic Curling final' and 'David Attenborough's Curling commentary'. To exemplify, and as illustrated by the screengrab below, the BBC's online coverage of the Winter Games across devices on February 21th 2014 featured live streams from the Men's Curling Finals; Men's Ice Hockey Semi-finals; Women's Biathlon; and Speed Skating Pursuits. In addition, the BBC site and mobile interfaces had a 'feature' section with 'Ten things you didn't know about Curling'; an interview with George Clooney on his fascination with the sport and a minidocumentary on its popularity in Scotland. Thus, in their live coverage of the sporting events of the Sochi Winter Olympics and Paralympics Games, the BBC and Channel 4 created platforms which allowed enhanced viewing 
of simultaneous events in real time, and facilitated user experiences where the user could stay with and immerse him or herself in the content on one device, whilst interacting with other viewers through another device.

\section{Figure 1. BBC laptop graphic user interface from Men's Curling Finals, Sochi Winter Olympics 2014}

Enhancing live televised events with media meshing evidently adds to the viewer's experience of the event as the volume of tweets and level of social media activity attest (Kleinman, 2013; Ofcom, 2013a: 33-41 and 150152). The BBC recorded a total of $5 \mathrm{~m}$ 'Live'l'As it happened' unique browser views, and $6.5 \mathrm{~m}$ globally over the course of the Winter Olympics. There were 10 million clip requests and two thirds of those came from live pages. The official hashtag \#sochi2014 was tweeted over 3.5 million times, with Curling, Figure Skating and Ice Hockey the most mentioned sports on Twitter throughout the Olympics. Nearly $45 \mathrm{~m}$ people chatted about the Winter Olympics on Facebook throughout the Sochi Games, for a total of $120 \mathrm{~m}$ combined posts, comments and "likes". In his comparison of three social media measurements of social TV in the US Philip Napoli demonstrates that measuring methods and their results diverge, and that it is difficult to ascertain what precise dimension of audience engagement are meaningfully measured (2013). While noting these limitations in terms of precise measurement, a high volume of traffic on social media platforms clearly occurs around live TV broadcasts. Also, TV networks clearly attribute meaning and value to this data which they use to supplement Audience Appreciation Indexes (AAI) and viewing figures. It is therefore pertinent to examine the content of and communication that takes place within these tweets and reflect on the kind of experience generated through this social media activity.

\section{Communication Between Broadcasters and Viewers}

It is notable that in their coverage of the live events broadcasters neither seek to facilitate nor encourage viewers/users interaction with the on-screen content. In the BBC's coverage of the Sochi 2014 Winter Olympic, and Channel 4's Winter Paralympics coverage, interaction between users and producers was limited to email, SMSes or tweets that notably are not displayed live on television or embedded in the BBC's online or mobile GUls. This can only be seen as a deliberate interface choice: the technology to relay SMS messages, instant messaging and tweets live on air has existed for well over a decade, and embedded twitter feeds are a common 
interface feature in other broadcast genres as well as in live events in other countries with public service broadcasters across the world, for example Denmark, Finland, Australia and Japan.

The BBC did provide a twitter feed (@bbcsochi2014), a variety of hashtags and a Facebook site but otherwise let the conversation unfold elsewhere on other sites, networks, the many affiliated social media sport fan apps available (e.g. fanatix, sportsapp, playup, etc.), or on clips sharing sites like Vine or Grabyo. Although there were ample tweets, comments and comments on social networks from the BBC's presenters, production team and the social media editors employed by broadcasters (according to Bulkley this is common practice (2011 as cited in Doyle 2013a), the majority of this was live commentary or information about other events. For example, presenters and commentators would flag up and publicise parallel streams of coverage of rival events in their live commentary, and repeat these announcements in the official @bbcsochi2014 twitterfeed as well as in the \#sochi2014 and related hashtags. Similarly, there was little direct engagement, communication or interaction between producers/presenters and viewers/users.

Although the viewers can choose between streams on four devices, and have to opportunity to email or text/SMS the production teams, the communication that takes place is a traditional broadcast model of transmission from one to many.

\section{Communication Amongst Viewers}

While the level of interaction between viewers was colossal, the conversation on Facebook and Twitter was predominantly phatic and expressive, to use Roman Jakobson's terms (1958), resembling that of friends watching, joking and commenting on the onscreen action. A selection of some of the tweets that ran simultaneously with live coverage of the Canada versus UK Men's Curling final on February $21^{\text {st }}$ illustrates this. Curling was one of the most popular sports index in the UK during the Olympic fortnight with 0.2 million browser impressions. It was among the top three tweeted-about topics, and there were over 75,000 mentions of \#LoveCurling during the Winter Olympics (statistics from BBC's Press office, August 2014). The screen grab below captures a representative selection of tweets with the hashtags \#bbcsochi and \#lovecurling (and, as the final unfolded, also \#hatecurling). These were captured with Snagit as part of a live netnograhic study of activity across simultaneously devices and in real time during the Curling final. 
MSC figure 2. Examples of tweets with \#bbcsochi concurrent with Mens' Curling Final, Sochi 2014.

A very similar scenario surrounded the live broadcast of the participation of the legendary Jamaican bobsleigh team. Here tweets with the hashtags \#bbcsochi, \#bobsled and \#JamaicaBobsled sparked a flurry of comments, in-jokes, and references to the feature film Cool Runnings (1993) about this bobsleigh team - immediately followed by a heated discussion about the correct title of the film (Cool Running/s) as well as if the correct quote is 'feel the rhythm', 'feel the beat' or both.

The type of communication that predominantly takes place in these tweets resonate with Pauline Tuomi's findings of social TV and tweeting along to live events in Finland. Tuomi analyses the texts and tweets that were broadcast live alongside live events that were televised by the Finnish broadcaster YLE. Analysing 3005 audience tweets published on Text TV during the Eurovision Song Contest, Independence Day and the Finnish election in 2011 in her conference proceedings, Tuomi highlights the informal and conversational nature of the majority of tweets. She concludes that the content of tweets seek to create the effect of a collective TV viewing experience and 'the idea of presence' that together bring additional value to the television experience (2012: 253-254).

In these ways the point of media meshing is not to replicate being present at the event, but to provide the viewer with as many vantage points as a television as a medium affords by allowing him/her to chose between multiple, simultaneous events or matches, and at the same time allow him/her to take part in the conversation that unfolds on social networks on a different device. That is, a typical viewer experience would be to watch and jump between the six live streams of footage from the BBC's coverage of different sporting events (or, as it may be, the same event or sport, but jumping between different simultaneous contests and competing teams) at Sochi on one device - TV, laptop, smartphone or tablet - whilst simultaneously tweeting about this, posting on social networks or engaging with other fans of the event on one of the many Winter Olympic apps available on Google Play or iTunes via a different device, for example a tablet, smartphone or PC. Thus, interestingly, the social experience for an individual watching a live event across screens created by the TV networks resembles one of watching an international event with friends and family at home on TV. 
This points to a readjustment of how live television and liveness is perceived and used strategically by the TV channels. By combining the reach of their networks with the ability to broadcast live media events and command a presence across devices, TV networks are reinventing and reasserting the notion of liveness as a unique selling point for television as a medium. Today, TV networks create live media events and experiences that their online competitors that deliver VOD and streamed content cannot compete with. They simply do not have the finance, reach, technology, facilities nor brand to compete with the established TV broadcasters, who conceptualised these type of viewing experiences as specifically televisual.

\section{Live is More}

Nicholas Christakis and James Fowler point out that digitisation does not change what we do, but the ways in which we do it (2009). This goes for audiences as well as broadcasters and new audiovisual content providers. The audience will still speak about programmes and content, but have now substituted the chat around the watercooler with social networks like Twitter, Snapchat and Facebook (Bettridge, 2011 as cited in Doyle, 2013a: 118-119). The TV networks are still in the business of delivering eyeballs on screens, but with multi-platform, the TV networks can deliver more eyeballs to more screens. Moreover, today, TV networks are using television's traditional traits - reach and live events - in a bid to dominate the mediascape and exert its power over who wins viewers across platforms and devices.

In addition to dominating the airwaves whilst the live event takes place, these events also increase the online presence and clout of the network that delivers the event in the media market. This accounts for the increase in programmes advertising and promoting themselves as live without being actually being transmitted live, e.g. Lambing Live (BBC, April 2014) Piping Live (BBC Scotland, June 2014) as well as the encouragement to continue the conversation "live" on twitter, for example in the BBC's weekly debate programme Question Time although the programme is clearly not transmitted in real time.

In addition to reaching a large simultaneous audience, TV networks can encourage and facilitate communication on second or third screens and devices, and in this process freeload on the activity on and availability of social networks. This has several advantages for the TV networks. 
First, social network activity offers TV networks and programme/content producers far more detailed and granular qualitative measuring and monitoring of audience preferences, behaviours, and viewing practices in real time as noted by Napoli $(2011 ; 2010)$ and Doyle (2013a: 119). By tweeting, retweeting and commenting on social networks the audiences feed back their viewing preferences, comments, likes and dislikes to broadcasters in general and, in the case of Channel 4 and other similarly funded broadcasters, advertisers. In addition to comments and activity on social networks in relation to televised content, mobile platforms also offer other ways of collecting audience details and data. In order to watch BBC content on smart phones or tablets it is necessary to download the BBC Media Player app from for example GooglePlay or App Store. Although this is free, the process registers mobile phone numbers, personal details and data. Although in this process the BBC only collates personal details 'in the most data protective and sensitive ways' and does not monitor or record user journeys, according to Chris Condron, the ability to do so is certainly there and could provide ways for the BBC to obtain and record viewing patterns from individual viewers. This qualitative and quantitative data supplements BARB viewing figures and Audience Appreciation Indexes. Similarly, as the viewers watch on laptops and computers the IP address records hits and browser impressions, and the content of activity on social networks can be - and is - scraped and used, not only to monitor audience behaviour, but also, as Philip Napoli also points out, to predict future demand of audiences, or to serve as content in its own right (2014).

Secondly, the audiences' interactions on social networks interactions become free content in itself for producers to use as Napoli also suggests (2014). Tweets and Facebook comments become content on websites, or curiosa and questions for radio shows and daily news roundups. Network traffic becomes news items in itself with news programmes reporting on YouTube hits, the number of tweets at Wimbledon or Children In Need as further evidence of the importance and significance of these media events. Even photos and footage of the audiences, sent to the TV networks by audiences and beamed back to themselves and to the world at large, turn into content in the coverage of the event itself. In these ways live televised events provide TV networks with ways of obtaining material and content from the audiences for free, at the same time as they reinforce the prominence of the event, the decision to televise it and the central role of the broadcasters in this process.

Thirdly, orchestrating and encouraging social media activity around its live events across different platforms, offers the TV networks that have the scope and scale to command large audience shares other organisational, 
economic and regulatory advantages. TV networks today take full advantage of the communities that emerge and interact around their content on social networks. Rather than trying to control the full 360-degree experience, which would be an impossible and unpractical task, the TV networks enrich the viewing experience by simply providing viewers with a FB page and a hashtag and let the conversation unfold. Broadcasters not only outsource social network activity, they also actively encourage it - crucially without seeking to host or curate this on their own platforms or sites. In doing so they freeride on the affordances of Twitter and Facebook gather momentum and boost attention around TV live events. On social networks viewers' tweets and comments become free advertising for the BBC's programmes - Chris Condron calls it 'marketing collateral'. This has additional cost-saving and regulatory advantages. By outsourcing and piggybacking on the debates around their programmes to social networks, the TV networks do not need to build, host, moderate and facilitate such debates on their own sites. Similarly, because conversations and comments do not take place on the TV networks sites, it removes the responsibility from the broadcasters to regulate tweets, comments and posts. In these ways TV networks effectively freeload and utilise many of the benefits and affordances of social networks and online sites without bearing the costs that come with building, maintain and regulating these - to return to Jeff Bewkes comments: 'TV is taking over the internet not the other way around'.

\section{Back to the Future}

It is in this context that the notion of live television is being redefined. Liveness on television can no longer be seen solely in terms of the temporal immediacy between the transmitted event and the receivers of this TV coverage. It has to be understood in the context of the entire multi-platform and interactive mediascape that it is part of, and evolving around, as well as in relation to the dynamics between devices, platforms and content providers.

Today, both the BBC and Channel 4 are using two of their core strengths, reach and live TV, to enhance the experience of watching live TV across screens and devices. They do so in order to become the cultural lynchpins for high profile media events that are then viewed on and interacted with across platforms and devices, but that always revolve around the original TV broadcasters and are orchestrated as TV viewing experiences. Twitter 
and Facebook are relegated to the ancillary but essential function of promoting the broadcasters TV content as well as literally 'bringing home' the event for the viewer to chat about with whomever is on social media at the time and wherever (s)he might find him or herself: on the sofa, in bed, on the bus or in the park, whether watching on mobile phones, tablets or massive widescreens.

Interaction between people via text messaging, instant messaging, micro-blogging and on social networks are usually seen as net-based activities. In combining these activities with liveness on television and the power to reach the largest simultaneous audiences, TV networks have a unique formula for free-riding on the affordances of social networks and apps, whilst capturing and holding its users across screens and platforms. In these ways TV networks enrol the affordances of the internet and social networks in the live televisual experience, whilst reasserting their positions as a cultural anchorage points across platforms. Today, the TV networks are using live media events to win eyeballs over from the online audiovisual content providers by creating the enhanced experience of watching TV as though at home surrounded by friends and family.

\section{Perspectives}

The findings presented here points to increasingly complex interactions across platforms and devices, and call for further and more nuanced research into connected viewing, multiplatform content and consumption. This opens up for new areas and topics in need of exploration as well as an expansion of the theoretical paradigm of scholarly work within this field.

The various new systems, models and mechanisms for delivering connected viewing experiences give rise to the invention of new formats, products, apps as well as new business models, constellations of content providers and creators and interactions across platforms and devices. This will also challenge current IP and copyright regimes and regulations. Comparing the strategies of commercial networks and Public Service Broadcasters would provide fruitful insights into the commercialisations of these new products and business models. Similarly, comparative and multidisciplinary studies of national and international polices, regulation, copyright and IP legislation around connected viewing practices and products would greatly enhance our understanding of the multiplatform mediascape today. 
John T Caldwell's second shift aesthetics (2003) and Henry Jenkin's theories on transmedia storytelling and content (2006) have been hugely influential for and successful in informing antecedent scholarly understanding of multiplatform content and strategies as well as in theorising how users travel across and between platforms. However, as internet-enabled devices proliferate, user behaviours become increasingly complex and it is necessary to take into account the type and temporality of the multiplatform content in order to interpret these various behaviours. In particular, different user and interaction patterns - and with it different multiplatform and connected viewing strategies - emerge depending on if the content is a live transmission of a media event, or if it is pre-recorded content.

As connected and two screen practices viewing increasingly become common and every day practices, there is a need for further and more nuanced research into multiplatform and connected viewing strategies of broadcasters and how these are orchestrated. In this, it is necessary to take into account not only how these strategies are influenced by viewer/user behaviour, but also the type and temporality content in question.

\section{Cited Interviews}

Chris Condron, BBC Head of Product and Sports. Media City UK, Salford Quays. August 2014.

Stuart Cosgrove, Head of Creative Diversity Channel 4, Channel 4 Nations and Regions, Glasgow, May 2010.

\section{Thanks}

I would like to thank the interviewees for sharing their time and insights, David Turnbull from BBC's Press Office for providing figures and facilitating visits to Media City UK as well as XXX XXX XXX, XXX XXX XXX and XXX $X X X X X X$ at $X X X, X X X X X X X X$ for excellent, thoughtful and inspiring feedback. 


\section{Bibliography}

Auslander P (2008) Liveness : performance in a mediatized culture. London: Routledge.

Author Removed (2013).

Author Removed (2014).

BBC (2013) Director-General Tony Hall unveils his vision for the BBC. London: BBC.

Bennett J (2007) From Museum to Interactive Television: Organising the Navigable Space of Natural History Display. In: Lyons J and Plunkett J (eds) Multimedia Histories : From the Magic Lantern to the Internet. Exeter: University of Exeter Press, 148-163.

Bennett J (2008) Interfacing the Nation. Remediating Public Service Broadcasting in the Digital Television Age. Convergence: The International Journal of Research into New Media Technologies 14(3): 277-299.

Bennett J (2011) Architectures of Participation. Fame, Television and Web 2.0. In: Bennett J and Strange N (eds) Television as Digital Media. Durham and London: Duke University Press, $332-$ 358.

Bennett J, Kerr P, Strange N, et al. (2012) Multiplatform Public Service Broadcasting. The economic and cultural role of UK Digital and TV Independents. London: Royal Holloway, University of London.

Bennett J and Strange N (2008) The BBC's Second-shift Aesthetics: Interactive Television, Multiplatform Projects and Public Service Content for a Digital Era. Media International Australia 126(2): 108-119.

Bennett J and Strange N (2011) Television as Digital Media. Durham and London: Duke University Press.

Boyle R (2014) Television Sport in the Age of Screens and Content. Television \& New Media 15(8): 746-751. 
Boyle R (Forthcoming 2015) Battle for Control? Copyright, Football and European Media Rights. Media, Culture \& Society 00(0).

Boyle R and Whannel G (2010) Three Interviews. Convergence 16(3): 355-368.

Brundson C (2010) Binging on box-sets: the natinional and the digital in television crime drama. In:

Gripsrud J (ed) Relocating Television. Television in the Digital Context. London \& New York: Routhledge, 63-75.

Caldwell JT (2003) Second-shift media aesthetics. Programming, interactivity and user flows. In: Everett A and Caldwell JT (eds) New media: Theories and practices of digitextuality. New York: Routledge, 127-145.

Caldwell JT (2006) Critical Industrial Practice: Branding, Repurposing, and the Migratory Patterns of Industrial Texts. Televison and New Media 7(2): 99-134.

Caldwell JT (2011) Worker Blowback. User-Generated, Worker-Generated and Producer-Generated Content within Collapsing Production Workflows. In: Bennett J and Strange N (eds) Television as Digital Media Durham and London: Duke University Press, 283-310.

Caughie JT (2000) Television drama : realism, modernism, and British culture. Oxford: Oxford University Press.

Chamberlain D (2011) Scripted Spaces: Televison Interfaces and the Non-Places of Asynchronious Entertainment. In: Bennett J and Strange N (eds) Television as Digital Media. Durham and London: Duke University Press, 230-255.

Christakis NA and Fowler JH (2009) Connected: the surprising power of our social networks and how they shape our lives. New York: Little, Brown and Co.

Crisell A (2012) Liveness and recording in the media. New York: Palgrave Macmillan.

Dayan D and Katz E (1992) Media events : the live broadcasting of history. Cambridge, Mass. ; London: Harvard University Press.

Doyle G (2011) From Television to Multi-Platform. Less from More or More for Less? Convergence: The International Journal of Research into New Media Technologies 16(4): 1-19. 
Doyle G (2013a) Innovation in use of digital infrastructures: TV scheduling strategies and reflections on public policy. In: Storsul T and Krumsvik A (eds) Media Innovations. Gothenburg, Sweden: Nordicom, 111-125.

Doyle G (2013b) Understanding media economics. London: SAGE.

Financial Times Live (2013) Keynote CEO Session: Driving Future Digital Growth. Avaliable at: https://www.ft-live.com/ft-events/ft-digital-media-conference-2013/sessions/keynote-ceosession-driving-future-digital-growth

Gray J (2010) Show Sold Separately : Promos, Spoilers, and Other Media Paratexts. New York: New York University Press.

Iosifidis P, Steemers J and Wheeler MPD (2005) European Television Industries. London: BFI.

Jakobson R (1958) Closing Statement: Linguistics and poetics. In: Seboek T (ed) Style in Language. Indiana University: Published in David Lodge (1988) Modern Criticism and Theory. A Reader. London \& New York: Longman, 32-57.

Jenkins H (2006) Convergence Culture: Where Old and New Media Collide. New York ; London: New York University Press.

Kleinman Z (2013) Wimbledon causes surge in social media. Avaliable at: http://www.bbc.co.uk/news/technology-23225501

Kozinets RV (2010) Netnography. Doing Ethnographic Research Online. London: Sage.

Levine E (2008) Distinguishing television: the changing meanings of television liveness. Media, Culture \& Society 30(3): 393-409.

Lotz AD (2009) Beyond Prime Time: Television Programming in the Post-Network Era. New York ; London: Routledge.

Marriott S (2007) Live television : time, space and the broadcast event. London: SAGE.

Napoli PM (2010) Revisiting 'mass communication' and the 'work' of the audience in the new media environment. Media, Culture \& Society 32(3): 505-516. 
Napoli PM. (2011) Audience evolution : new technologies and the transformation of media audiences. New York; Chichester: Columbia University Press.

Napoli PM (2013) Social TV Engagement Metrics: An Exploratory Comparative Analysis of Competing (Aspiring) Market Information Regimes. Paper presented at the annual meeting of the Association for Education in Journalism \& Mass Communication. Washington DC: Fordham University Schools of Business Research Paper No. 2307484.

Napoli PM (2014) On Automation in Media Industries: Integrating Algorithmic Media Production into Media Industries Scholarship. Media Industries Journal 18(1): 35-38.

Ofcom (2013a) The Communications Market Report: United Kingdom. The reinvention of the 1950s living room. Available at: http://stakeholders.ofcom.org.uk/market-data-research/marketdata/communications-market-reports/cmr13/uk/.

Ofcom (2013b) The reinvention of the 1950s living room. Available at: http://media.ofcom.org.uk/2013/08/01/the-reinvention-of-the-1950s-living-room-2/.

Steemers J (2004) Selling Television: British Television in the Global Marketplace. London: BFI.

Steemers J (2014) Selling Television: Addressing Transformations in the International Distribution of Television Content. Media Industries Journal 1(1): 44-49.

Strange N (2011) Multiplatform Public Service. In: Bennett J and Strange N (eds) Television as Digital Media. Durham and London: Duke University Press, 132-157.

Tuomi P (2012) Text-TV + Twitter= A new form of social TV? Paper presented at MindTrek '12 - the 16th International Academic MindTrek Conference ACM New York, NY, USA.

Ytreberg E (2009) Extended liveness and eventfulness in multi-platform reality formats. New Media \& Society 11(4): 467-485. 
1 This either in real time or near real time. Live broadcasted content is often delayed by a few minutes in the UK to safeguard against unforeseen obscenities, illegalities or disasters and in this way adhere to OFCOM regulations.

2 David Booth was speaking to Media Management MSc students at Centre for Cultural Policy Research at the University of Glasgow in October 2013. 